\title{
Geomorphic rehabilitation in Europe: recognition as best available technology and its role in LIFE projects
}

\author{
JF Martín Duque Complutense University of Madrid, and Geosciences Institute, Spain \\ M Tejedor Complutense University of Madrid, Spain \\ C Martín-Moreno Complutense University of Madrid, Spain \\ JM Nicolau University of Zaragoza, Spain \\ I Zapico Complutense University of Madrid, Spain
}

\begin{abstract}
Geomorphic rehabilitation ([GR], also known as geomorphic reclamation or geomorphic restoration) is a general term to describe alternative methods and procedures to conventional mine rehabilitation. The main aim of GR is to replicate 'natural' landforms for the new conditions after mining and to restore functionality and diversity of ecosystems at degraded sites. The correct application of the GR technique ensures visual integration with surrounding landscapes. Although $G R$ is a broad term, referring to any geomorphic restoration of land, $G R$ is often synonymous with fluvial GR, mostly following the GeoFluv' ${ }^{T M}$-Natural Regrade method.
\end{abstract}

This paper describes how and why the application of GR through Geofluv-Natural Regrade in Spain since 2009 has attracted formal recognition by the European Commission (EC) of the European Union (EU) as one, among others, of a catalogue of best available techniques (BATS) for the management of waste from extractive industries, in accordance with the European Directive 2006/21/EC. GR has been recognised as $B A T$ at the EU for multiple reasons, including mine site monitoring results that demonstrate increased physical stability with minimised erosion from stormwater and snowmelt runoff; natural hydrological function being established; the variability within the formed landform promotes ecological diversity for vegetation and wildlife communities; construction and short and long-term maintenance and repair costs are minimised; and visual impact of the mined landscape is reduced.

This paper describes also the role of GeoFluv-Natural Regrade GR in the L'Instrument Financier pour I'Environnement (LIFE) program, which is the EU's most important funding instrument addressing environment and climate action. A focus is provided on the LIFE TECMINE project, described in detail, since it is the most recent and complete GeoFluv-Natural Regrade example in Europe.

The TECMINE project is a geomorphic-based ecological restoration project in the Valencia province, within the Iberian Mountain Range and where conventional mine rehabilitation practice, based on gradient terraces, shows general and widespread failure. The demonstration project is fostered by the Administration of the Valencia Region, which seeks to test innovative techniques (GR, micro-catchments, soil amendments and new protocols of revegetation) for mine rehabilitation, promote improved practices and disseminate the best practice output through their development and analysis. Testing GR is the main focus of the project.

The application of GR at the TECMINE project included (a) finding 'natural' and 'stable' landforms and landscapes to be used as reference or analogues for replication in GR, although difficult, was possible due to ancestral land transformation; (b) the steep terrain, characteristic of the lberian Range, challenged the formation of GR GeoFluv-Natural Regrade designs, but the project demonstrated that they can be implemented in that mountain setting; (b) the mining company reported similar cost estimations for this alternative GR rehabilitation (as-built) as that for a conventional restoration design (projected); (c) a holistic approach to GR, not dealing only with topography, allowed the identification and use of limestone colluvium 
as an adequate growth media for initiating soil development; this solution not used before for rehabilitation in this region provided a clear and advanced contribution from the project.

Keywords: geomorphic rehabilitation, GeoFluv-Natural Regrade, best available technology, LIFE program, mine closure, Spain

\section{Introduction}

The assessment of landform designs of different areas of a mining footprint (mostly final waste dumps) has been mainly tackled through the use of soil erosion models (such as RUSLE or WEPP) and landscape evolution modelling (such as SIBERIA or CAESAR) (Hancock et al. 2003). In parallel, methods and procedures to design landforms that replicate natural ones at lands altered by human activities, or that move earth and alter the natural landform, primarily by mines, have been also developed. The generic term to describe those methods and procedures is geomorphic rehabilitation (GR), also geomorphic reclamation or geomorphic restoration. The main aim of GR is to restore, through landform design, the functionality and appearance of natural landscapes (Martín Duque et al. 2010; Nicolau 2003). The complementary capability of soil erosion and landscape evolution modelling and geomorphic design tools has been evaluated (Hancock et al. 2019; Howard et al. 2011).

Although the idea of replicating natural landforms at mined sites has had many followers and practitioners within the umbrella of a landscaping approach, with most of the work unpublished, it must be said that there are only a few standardised and recognised scientific-based methods of GR with a truly geomorphic approach to topographic reconstruction (Toy \& Chuse 2005). The replication of natural cliffs and their adjacent scree/talus slopes has been common for the rehabilitation of limestone quarries in the United Kingdom since the late 1970s (Gagen \& Gunn 1988). This technique attempts to compress time by designing and building the rock cliffs or slopes that would tend to form and evolve with time, through falls and slides that occur preferentially on weathered rock or by fracturing rock with blasting. Equivalent natural rock cliffs and scree and talus slopes are used as analogues. The Rosgen $(1994,1996)$ method has been widely employed for perennial stream restoration in the United States (US), including numerous mined sites. RIVERMorph (2019) is design software based on the principles established by Rosgen. Rehabilitation of the Canadian oil sands allowed the development of a truly scientific geomorphic approach for designing sustainable drainage systems at mined lands (Sawatsky \& Beckstead 1996).

Although GR is a quite broad term, referring to geomorphic approaches to land restoration, GR is often synonymous with fluvial GR, and within that, mostly following the GeoFluv ${ }^{\top \mathrm{M}}$-Natural Regrade method, due to its widespread use.

The Fluvial Geomorphic Reclamation method GeoFluv - from geomorphic and fluvial (Bugosh \& Epp 2019) is a procedure for land rehabilitation that is able to replicate the complexity of natural landforms and drainage networks within catchments. It allows designing mature and stable landforms and landscapes those that would naturally form by erosional processes for the materials, climate and physiographic conditions at the site. The values of the design input parameters change in response to local environmental variability and have to be identified in local stable landform analogues. A detailed explanation of the GeoFluv-Natural Regrade method is provided at Zapico et al. (2018) and Bugosh \& Epp (2019), and we refer the reader to those papers.

As a synthesis, mine sites reclaimed with this technique become functional watershed systems. The drainage patterns of undisturbed lands are reproduced. Instead of the uniform terraces and linear slopes found as a result of mining, geomorphic landforms provide complex surfaces, with ridges and valleys and $\mathrm{S}$-shaped slopes. Small drainage paths are created and they converge into natural-looking and functional fluvial channels.

This technique began to be applied in 1999 at large coal mines of New Mexico, US, where it is now compulsory for such mines (NMMMD 2010). Its implementation sought to achieve long-term erosional stability, reduced maintenance, and increased biodiversity as compared to traditional mine rehabilitation 
landforms (e.g. terrace, berm, downdrains). Natural Regrade is commercial software, which was launched in 2005, that helps users to efficiently make GeoFluv designs in a CAD format (www.carlsonsw.com/). GeoFluv through Natural Regrade has been successfully applied in many mined sites within the US (i.e. Bugosh \& Epp 2019) and is being evaluated for the US Eastern states (DePriest et al. 2015). GeoFluv has been, and continues to be, used in Spain since 2009, with dozens of designed and constructed examples in place (i.e. Zapico et al. 2018). The method has also been employed in Australia (Kelder et al. 2016; Waygood 2014) and in South America (Bugosh et al. 2016).

The achievements of the GeoFluv-Natural Regrade GR projects in Spain resulted in 2018 Geomorphic Rehabilitation being recognised by the European Commission (EC) of the European Union (EU) as a best available technique (BAT) for the management of wastes of the extractives industries (Joint Research Centre [JRC] 2018). What a BAT is and how a particular approach comes to be recognised as a BAT are explained in detail in Section 2.

The novelty and innovative character of GR in the EU was essential to attracting funding for two L'Instrument Financier pour l'Environnement (LIFE) program demonstration projects (ECOREST CLAY and TECMINE), aimed at promoting innovation and capturing and disseminating best practice through their development and analysis. The LIFE program is the EU's most important funding instrument for the environment and climate action created in 1992 (ec.europa.eu/easme/en/life). The LIFE TECMINE project is the most recent and complete GeoFluv-Natural Regrade example in Europe, and is later explained in detail.

\section{$2 \quad \mathrm{GR}$ as Best Available Technique in Europe}

The EC is an EU institution formed to promote the common interest of EU members by proposing and enforcing legislation as well as implementing policies via an EU budget. In 2018, the EC approved and released the Best Available Techniques (BAT) Reference Document for the Management of Waste from Extractive Industries (MWEI BREF) in accordance with the European Directive 2006/21/EC. This publication is a Science for Policy report by the EU JRC. The JRC publication aims to provide evidence-based scientific support to the European policy-making process.

As defined by the EC, and referred to as the management of waste from extractive industries, BATs are:

"generic management and waste hierarchy techniques, risk-specific techniques to ensure safety, techniques for the prevention or minimisation of water status deterioration, techniques for the prevention or minimisation of air and soil pollution and other riskspecific techniques." (JRC 2018, p. 5)

More specifically, they are:

"The most effective and advanced stage in the development of activities and their methods of operation which indicates the practical suitability of particular techniques for providing the basis for emission limit values and other permit conditions designed to prevent and, where that is not practicable, to reduce emissions and the impact on the environment as a whole: (i) 'techniques' includes both the technology used and the way in which the installation is designed, built, maintained, operated and decommissioned; (ii) 'available techniques' means those developed on a scale which allows implementation in the relevant industrial sector, under economically and technically viable conditions, taking into consideration the costs and advantages, whether or not the techniques are used or produced in the Member State in question, as long as they are reasonably accessible to the operator; (iii) 'best' means most effective in achieving a high general level of protection of the environment as a whole." (JRC 2018, p. 610) 
A particular mine waste management technique becomes recognised and established as BAT through a process led by expert judgement of the EC's JRC team involving the following steps:

- Identification of the key environmental issues for the mining sector.

- Identification of the main mining operators within the EU, validated for representing a specific mining sector (i.e. aggregates, barytes, coal, kaolin, potash, salt, copper, lead, zinc...).

- Report by mining operators of the techniques most relevant to address these key issues, via questionnaires that must show evidences of success and examination by experts.

- Identification of the environmental performance levels achievable, on the basis of the available data in the EU and worldwide.

- Examination of the conditions under which these environmental performance levels were achieved, such as costs, cross-media effects, and main driving forces involved in the implementation of the techniques.

GeoFluv-Natural Regrade GR over mined land has been applied in Spain since 2009. Ten projects have been completed and dozens more are in the design phase. The most common mine setting is in clay and silica sand quarries of different types, mostly in mountainous terrain. GR is also proposed for the rehabilitation of limestone quarries, coal and metallic mines. Proven success demonstrated by mining companies (e.g. Caobar, the main kaolin producer of Spain) has led the EC to recognise GR as an optional BAT for the management of wastes of the extractive industries.

The most effective application of GR techniques is states as being when mining excavation and rehabilitation processes are integrated, as this offers maximum earth movement savings. Thus, placement of the generated extractive waste is planned to coincide with the design of the geomorphic landforms (i.e. valleys or ridges) according to the geomorphic design and following a program of progressive rehabilitation. Therefore, the general shape of the reclamation landform emerges as the excavation process progresses. This is the process preferred for active mines (Bugosh \& Epp 2019). For abandoned mines, cost-effective GR is achieved when the pattern of fluvial channels and ridges is adapted to the existing uplands and lowlands of the mine site so that earthwork is minimised.

GR is considered as a BAT because it has been proven to achieve multiple outcomes; that is, increase the physical stability, provide a natural hydrological function, minimise erosion from stormwater and snowmelt runoff (Zapico et al. 2018), provide a variation in the natural landform that promotes ecological diversity for vegetation and wildlife communities (Martín-Moreno et al. 2018a; Zapico et al. 2011), minimise construction, reduce short and long-term maintenance and repair costs, and reduce the visual impact.

\subsection{GR Spanish sites that attracted BAT recognition}

The example sites situated in Spain and referred to were:

- El Machorro and Maria José active kaolin mines (Caobar company).

- The Aurora clay quarry (Cemex company).

- The Somolinos and Nuria abandoned mines (JRC 2018, p. 401).

Figure 1 shows images of the geomorphic-based rehabilitation at the El Machorro active mine. Environmental performance and operational data were the reasons why the GR EI Machorro mine was recognised as BAT. GR was incorporated into the mine's operational plan since 2012. GR was carried out as a progressive rehabilitation process in-mountain mining. The measured annual values of erosion yielded $4 \mathrm{t} / \mathrm{ha} / \mathrm{yr}^{-1}$. These values were obtained by measuring the sediment yield at an outlet pond, described in Zapico et al. (2018). The mine surfaces are now stable in geomorphic terms and maintenance is not needed. Economic savings of EUR 55,000 per year have been estimated by applying geomorphic restoration in not having to clean and maintain settling ponds, according to the Caobar mining company. 

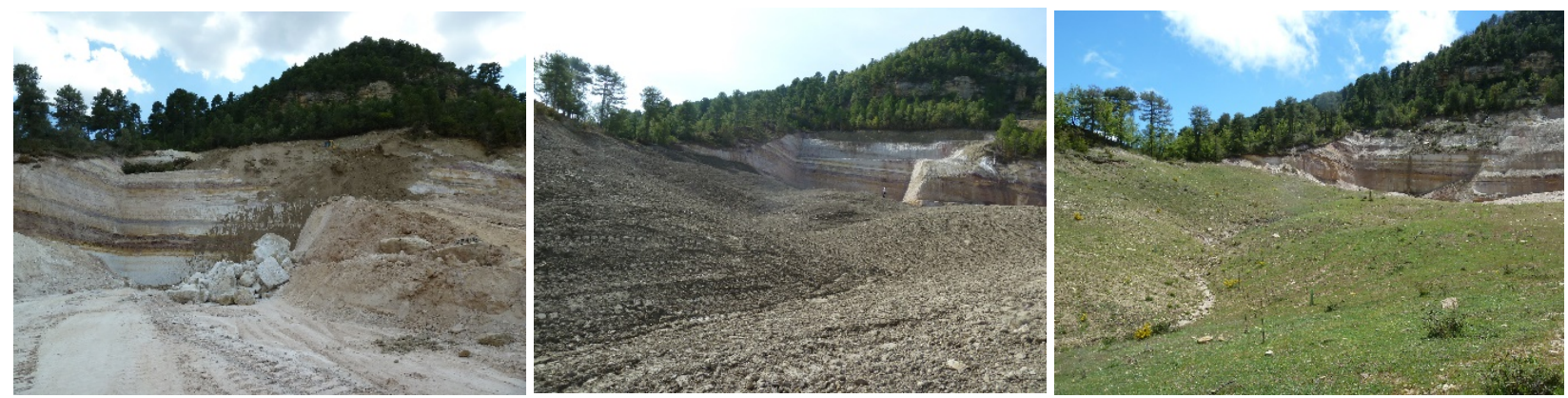

Figure 1 Geomorphic rehabilitation of a sector of El Machorro kaolin mine (Poveda de La Sierra, Guadalajara, Spain). Left, before rehabilitation (August 2012); centre, after landform regrading and soil replacement (October 2012); right, first stages of vegetation re-establishment (May 2014). Photos by José F. Martín

Figure 2 shows images of the geomorphic-based rehabilitation at the Somolinos abandoned mine. The reasons why the Somolinos example was recognised as BAT was due to the environmental benefits in limiting deterioration in surface water quality prior to rehabilitation, minimising soil erosion, providing a natural channel morphology to convey water, controlling sediment discharge and hydrological balance, and improving vegetation and habitat values (JRC 2018, pp. 399-400).
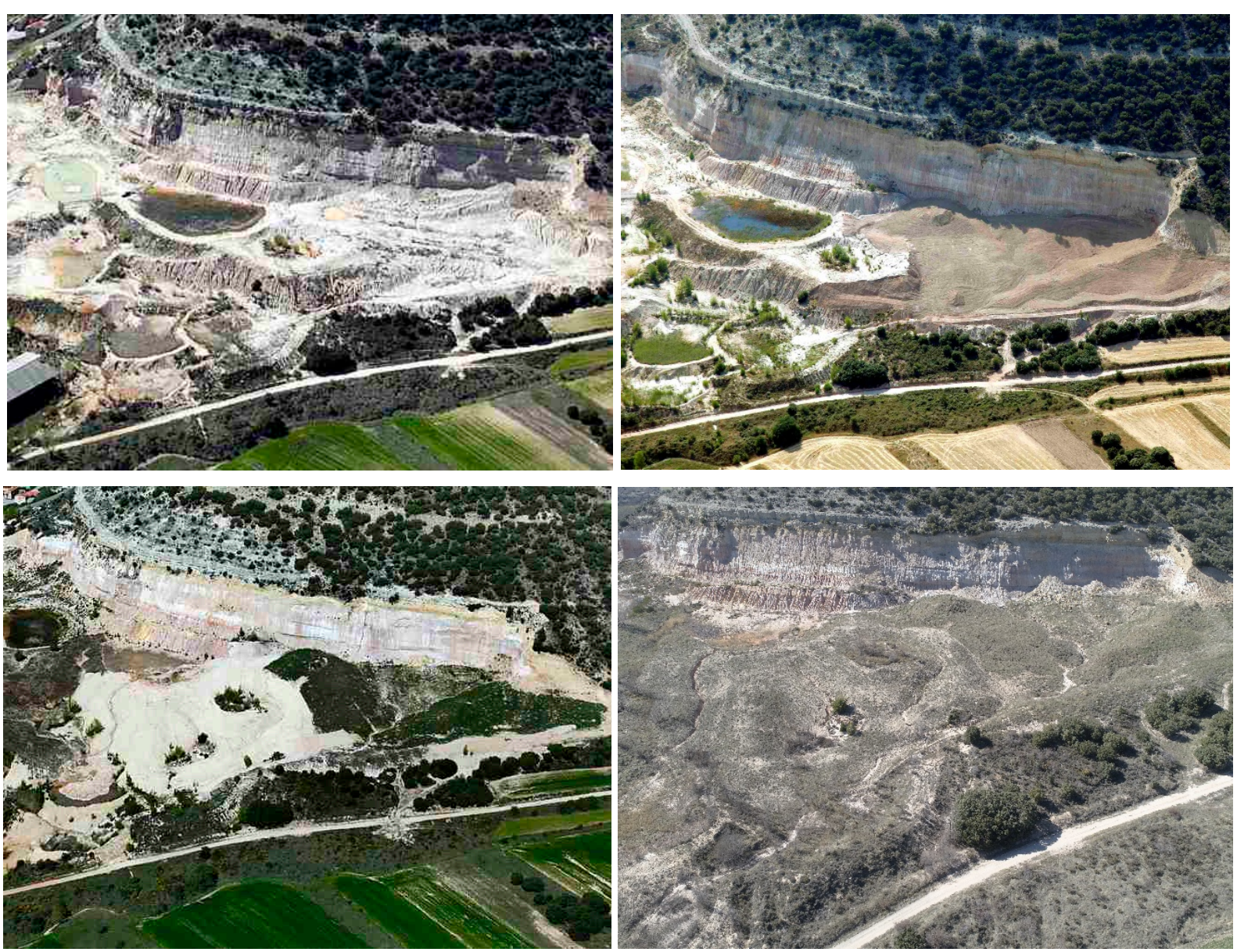

Figure 2 3D close aerial views of the Somolinos geomorphic-based rehabilitation. Upper left, April 2011 (pre-rehabilitation); upper right, June 2011, first phase; lower left, May 2014, after second phase; lower right, current state, March 2019. Photos by Paisajes Españoles SA 
Figure 3 shows images of the geomorphic-based rehabilitation of the Aurora active quarry. The Aurora example served in BAT recognition due to GR providing the hydrological connectivity between an ephemeral stream and a pond, which was interrupted by the extractive activity and in designing and building a new drainage network. The network consisted of a main meandering channel, connected upstream and downstream (stream and pond, respectively) and three sub-watersheds, connecting the natural surroundings with the mean channel by digging small valleys in the highwall. Scalloped convexconcave hillslopes were designed and built to drain into the channels. With subsequent soil replacement and revegetation, this landscape has demonstrated to be geomorphically stable, ecologically diverse and visually appealing. Martín-Moreno et al. (2018b), in the monitoring of this example, demonstrated that soil moisture content is higher in GeoFluv landforms than in the conventional, providing more moisture availability for plants.

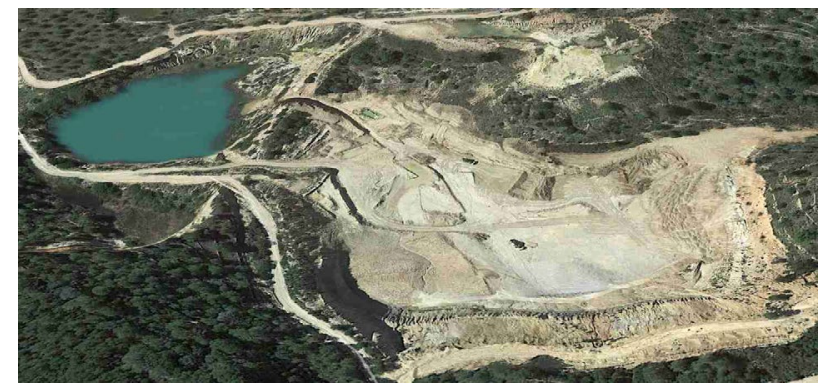

(a)

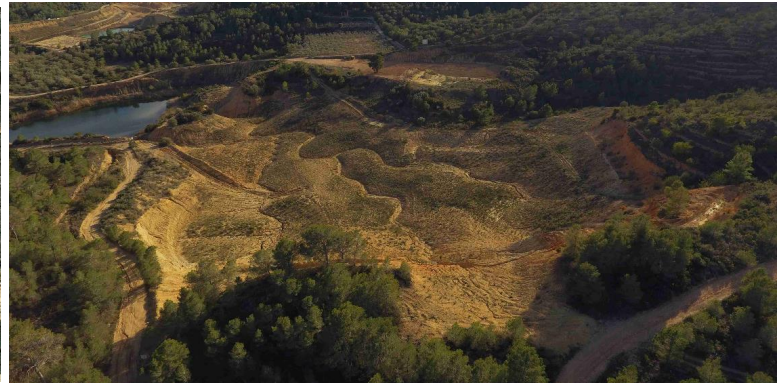

(b)

Figure 3 The Aurora geomorphic-based rehabilitation. (a) first advances of the geomorphic reconstruction (May 2015); (b) state in April 2018. LIFE ECOREST CLAY project. Photos by (a) Paisajes Españoles SA; (b) DIEDRO

\section{GR at the core of LIFE projects in Europe: the TECMINE project}

The first EU LIFE project including GR for mined sites was ECOREST CLAY (www.cemexrestaura.com/en/). GeoFluv-Natural Regrade was used within this project to offer GR design and was applied to three clay quarries, used to make cement by the Cemex company. Martín-Moreno et al. (2018a) provides a detailed description of GR applied to the project.

The second EU LIFE GR focused project was TECMINE - the central theme of this paper - which focused on two clay and silica sand mines of the SIBELCO mining company (Ademuz, Comunidad Valenciana, Spain) (www.agroambient.gva.es/en/web/life-tecmine/inicio). The sands were exploited for making glass and, along with kaolin, used for high-quality tile manufacturing. Within the Iberian Mountains of Spain, the physiographic setting consists of mountain slopes with limestone capping, a characteristic topography of mesas and cuestas and slopes underlain by silica sands and clay, draped by limestone colluvium. The soils are characteristic calcaric regosols within a typical Mediterranean forest dominated by holm oaks (Zapico et al. 2018).

The main aim of the project was to provide long-term stability in a regional framework where the conventional terraced benches on the rehabilitated waste dumps were highly unstable, with widespread gullying (Figure 4). The environmental conditions that favour such geomorphic instability are a combination of (a) highly erodible mine wastes (sands and clay); (b) high steep terrain, with long and steep hillslopes; (c) highly erosive convective summer rainstorms, typical of the Mediterranean climate; and (d) thin soils and low vegetation cover. These conditions, typical of the environment of the Iberian Mountains of Spain, had previously been characterised and quantified at a nearby location, where sediment yields of $353 \mathrm{t} / \mathrm{ha} / \mathrm{yr}^{-1}$ were recorded for rehabilitated areas identical to the ones shown in Figure 4 (Martín-Moreno et al. 2018b). 

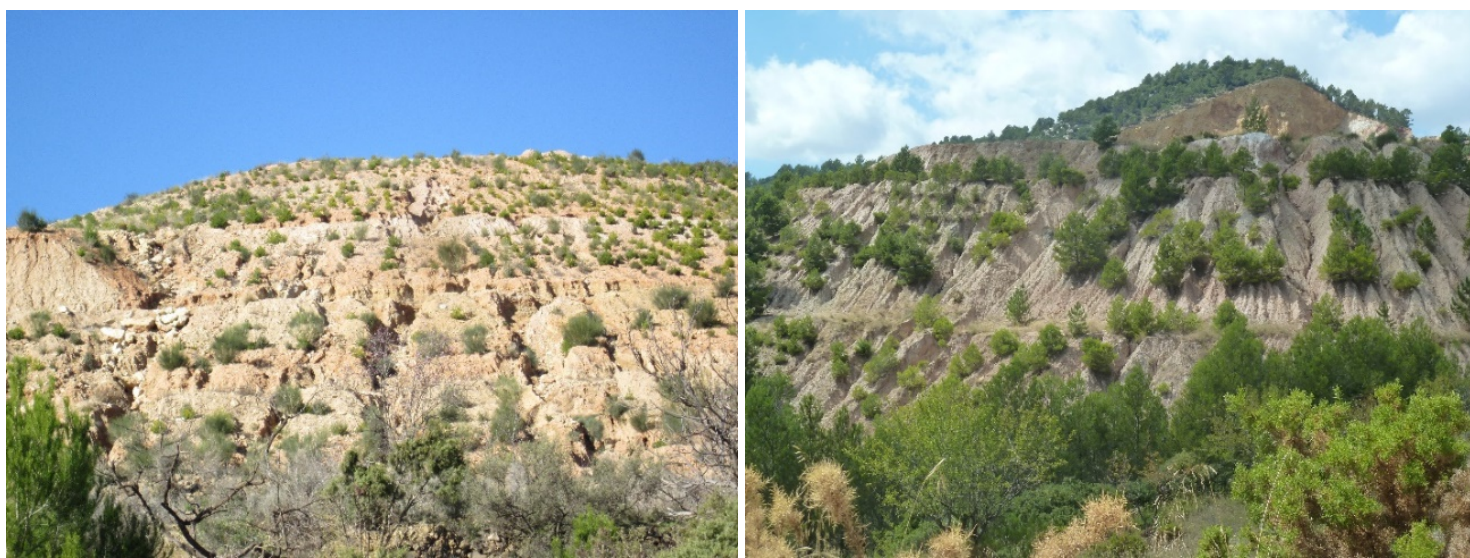

Figure 4 Conventional waste dump mine rehabilitation in the Valencian Iberian Range; terraced landforms with Mediterranean pine, showing widespread gullying (photos by José $\mathrm{F}$ Martín)

Therefore, the challenges of the TECMINE project were substantial in not only significantly reducing erosion but also building suitable soil substratum and re-establishing self-sustaining, diverse native vegetation cover and ecosystem from very challenging initial conditions. The performance of this project was to be instrumental and applicable in informing a whole series of similar mines in the region.

\subsection{GR methodology at the TECMINE project}

As a synopsis, the GeoFluv-Natural Regrade implementation at TECMINE included the following phases:

1. Locating stable natural landforms in physiographic conditions similar to the ones to be rehabilitated.

2. Analysing the starting topographic and hydrologic conditions of the areas to be rehabilitated.

3. Designing a functional watershed at the rehabilitation area through iterations with Natural Regrade.

4. Validating the design's functionality and stability (runoff tracking and shear stress analysis, among others).

5. Building the designed landforms.

6. Monitoring the hydrological and erosive-sedimentary behaviour of the geomorphic reclamation.

\subsection{GR results at the TECMINE project}

Suitable reference areas could not be found in the near surroundings of the mines subject to rehabilitation, due to intense, historical land transformation by humans (agriculture). However, reference areas and inputs used in similar physiographic settings were appropriate. They are described in detail in Zapico et al. (2018).

Figures 5 and 6 show the starting point, GR designs and built results for the two sites. The designs were carried out during the summer of 2018 and the building process lasted from September 2018 to April 2019. 

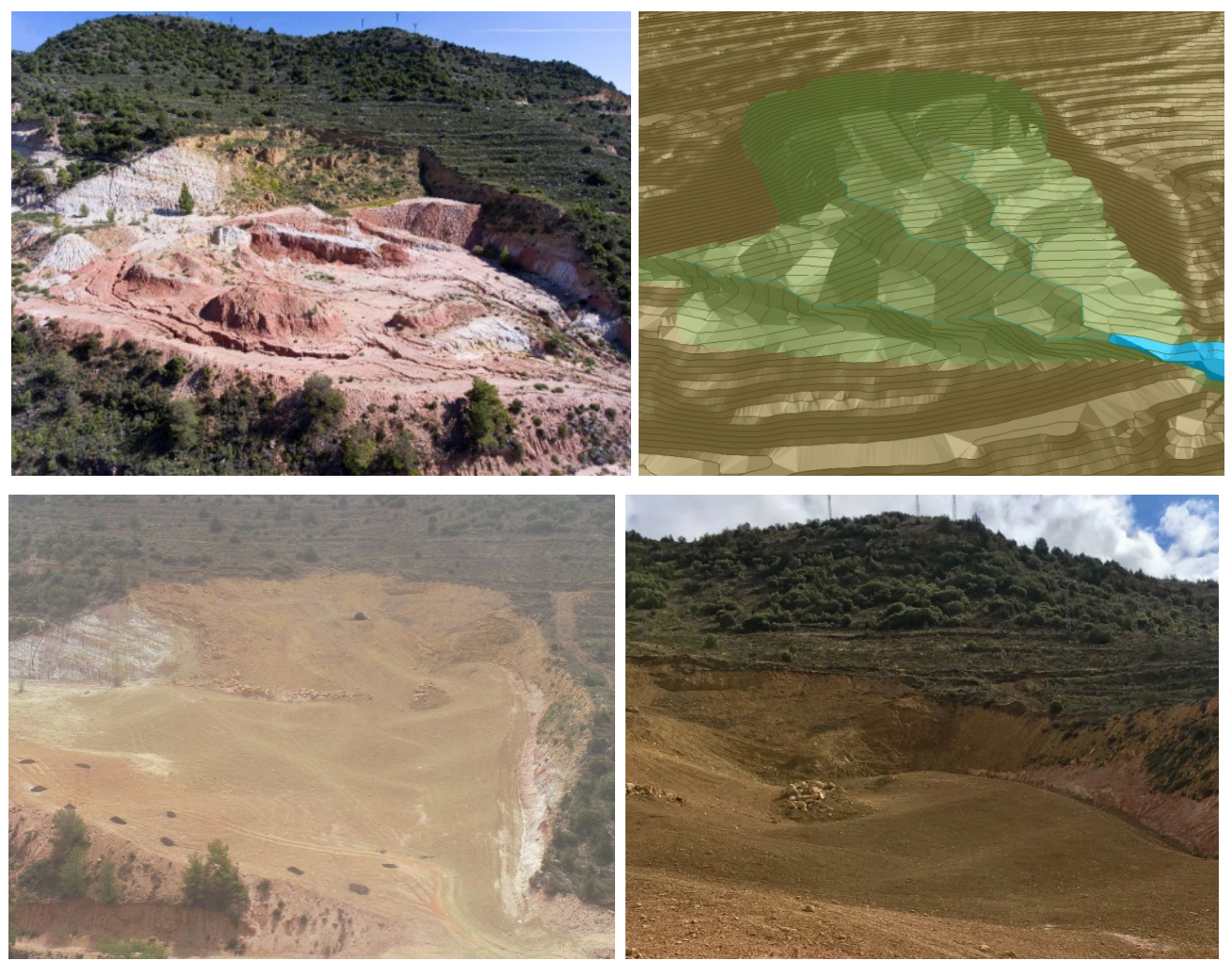

Figure 5 Eastern mine site of TECMINE. Upper left, aerial view pre-rehabilitation (July 2018, photo by Paisajes Españoles SA); upper right, 3D view of discrete element modelling of the GR design; Lower, left (aerial) and lower right (ground), views after GR regrading and colluvium spreading (photos by Vaersa)
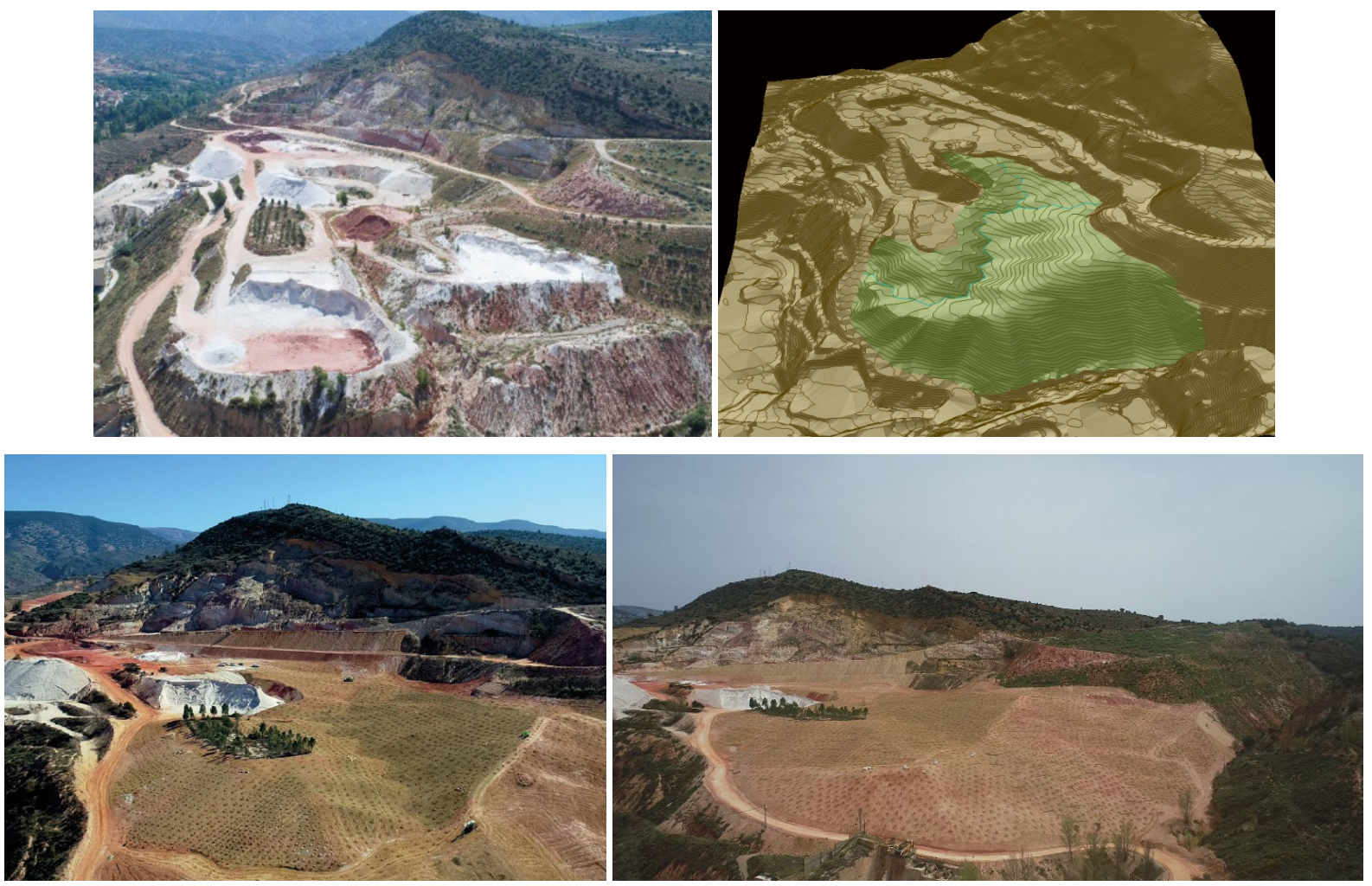

Figure 6 Western mine site of TECMINE. Upper left, aerial view pre-rehabilitation (July 2018, photo by Paisajes Españoles SA); upper right, 3D view of the GR design; lower left and right, aerial views after geomorphic regrading, colluvium spreading, seeding and planting (photos by Vaersa) 
The eastern site (Figure 5) has an area of 1.80 ha. Figure 7 shows the design and the cut-and-fill balance between the pre-rehabilitation state and the built one. In total, 17,358 $\mathrm{m}^{3}$ were cut and 5,691 $\mathrm{m}^{3}$ were fill. The exported difference volume, $11.667 \mathrm{~m}^{3}$, is the limestone colluvium, spread at the western site as growth media. The cut-and-fill map shows deeper cuts at the former slump affecting limestone colluvium.
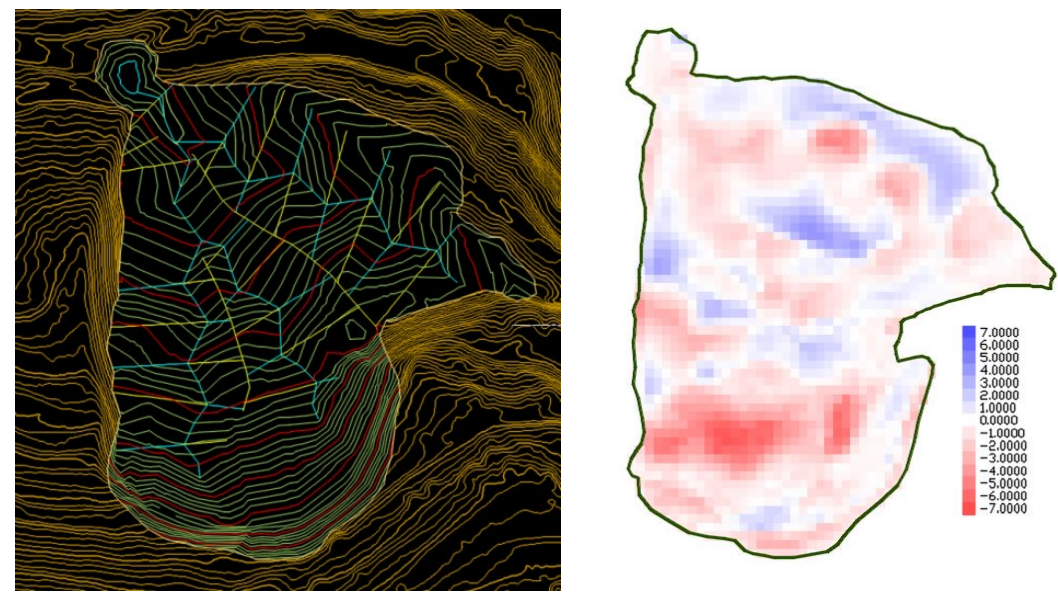

Figure 7 Eastern GR of TECMINE. Left, GR designed topography; contours are each $1 \mathrm{~m}$, with the index contours, in red, each $5 \mathrm{~m}$. Zigzag blue for channels, straight blue for swales, yellow for ridges and subridges. Right, cut-fill balance between pre-rehabilitation and GR rehabilitation. North in upwards position. No scale

The western site (Figure 6) has an area of 5.91 ha. Figure 8 shows the design and the cut-and-fill balance between the pre-rehabilitation state and the built one. In order to build the GeoFluv landforms, 132,733 $\mathrm{m}^{3}$ had to be cut and $32,479 \mathrm{~m}^{3}$ had to be moved to fill areas. Most of the cut at this example is at the edge of former platforms facing a western creek (foreground at Figure 6 upper left). Since 11,667 $\mathrm{m}^{3}$ of this fill was imported as limestone colluvium from the eastern GeoFluv, a total of $111,921 \mathrm{~m}^{3}$ were exported to stabilise the basis of the highwall, a condition specified in advance for an approximate volume.
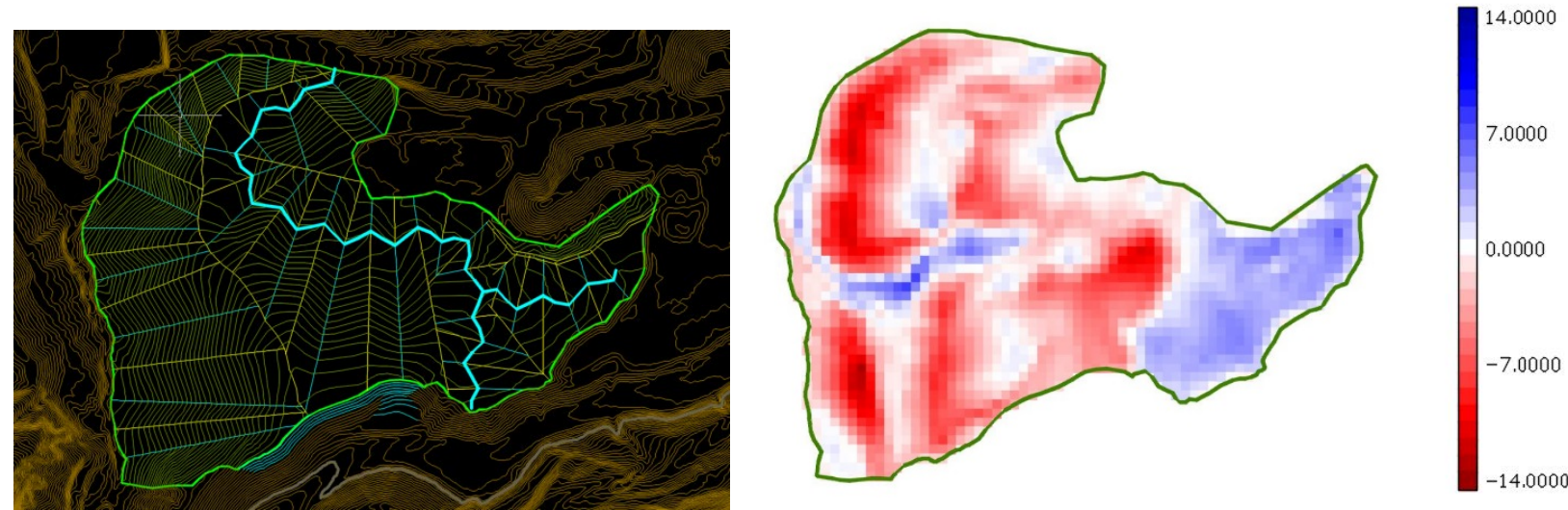

Figure 8 Western GR of TECMINE. Left, GR designed topography; contours are each $1 \mathrm{~m}$. Zigzag blue for channels, straight blue for swales, yellow for ridges and subridges. Right, cut-fill balance between pre-rehabilitation and GR rehabilitation. North in upwards position. No scale

After the earth movement finished, the mining company reported the same costs for this alternative GR rehabilitation (built) as that for conventional, terraced solutions (projected before the LIFE project, but changed after that).

Particularly difficult was identifying suitable earth materials to 'build' a soil. A detailed geomorphic analysis of the area identified a rotational slide (slump) with more than $10,000 \mathrm{~m}^{3}$ of limestone colluvium at the head of the eastern mine site to be restored (Figure 9). These materials are slope surficial deposits 
composed of limestone debris (gravel, sand, loam), which were eroded from the limestone caps above the silica sand and clay mined materials. They are not topsoil but subsoil; however, this subsoil is the substratum on which the original natural soils (calcaric regosols) develop and where local vegetation grows.
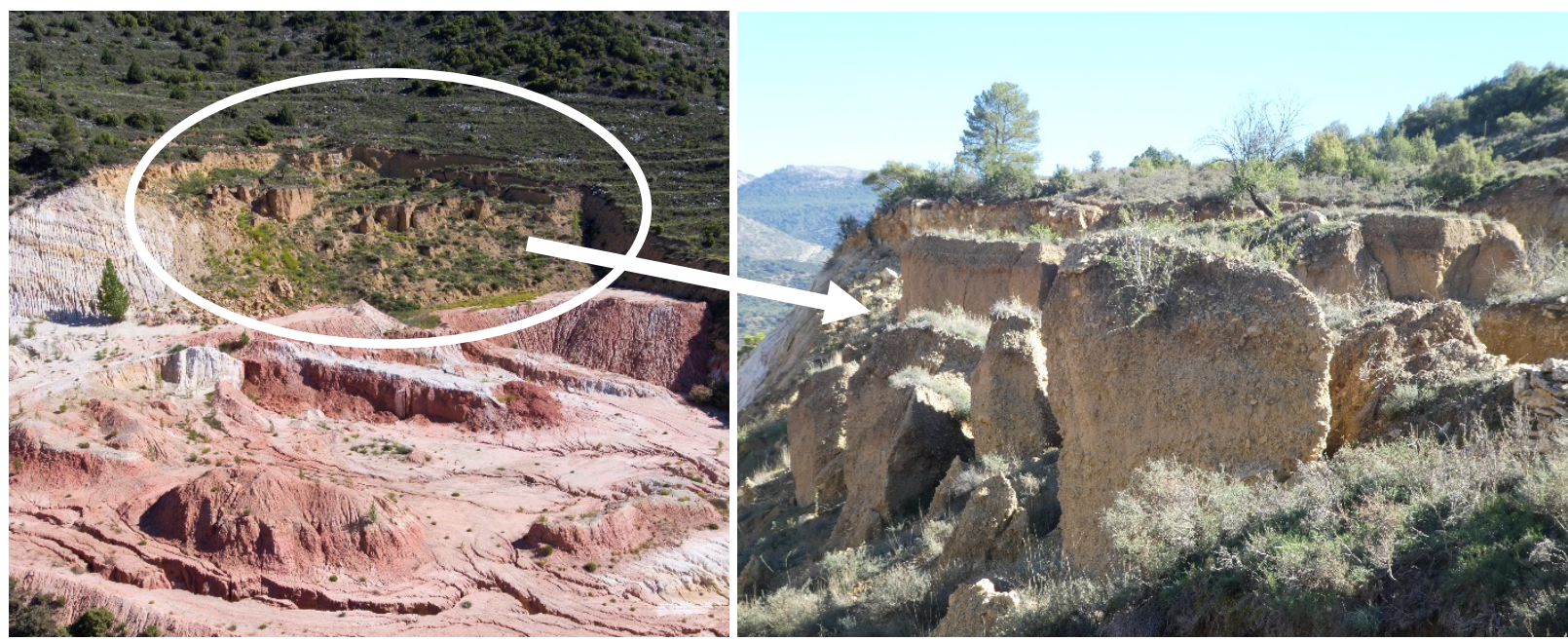

Figure 9 Left, Aerial view of one of the two sites subject to restoration at the TECMINE project. The white ellipse shows the head of a slump affecting limestone colluvium. Right, detail of the rotated and slump blocks, showing depths of colluvium higher than $7 \mathrm{~m}$

Table 1 presents physical and chemical properties of the limestone colluvium compared with the most common waste material at these mines. The content of total carbonates, organic matter or organic carbon, but mostly the physical advantages of stoniness and texture, favour the use of limestone colluvium as growth media.

Table 1 Comparison of selected soil properties for common mine wastes and limestone colluvium at the TECMINE project. Source: The Center for Environmental Studies of the Mediterranean (CEAM), unpublished data

\begin{tabular}{lllllll}
\hline & Stoniness (\%) & $\mathbf{p H}$ & $\begin{array}{l}\text { Total } \\
\text { carbonate (\%) }\end{array}$ & $\begin{array}{l}\text { Organic } \\
\text { matter (\%) }\end{array}$ & Org. C (\%) & $\begin{array}{l}\text { Soil texture } \\
\text { USDA }\end{array}$ \\
\hline $\begin{array}{l}\text { Sand waste } \\
\text { Limestone }\end{array}$ & 12.27 & 8.46 & $<0.5$ & 0.1 & 0.06 & Loamy sandy \\
colluvium & 65.46 & 8.92 & 39.28 & 0.38 & 0.22 & Loam \\
\hline
\end{tabular}

To complement the GR design, micro-catchments were created in the upper surface soils to capture precipitation, limit runoff and maximise infiltration thereby facilitating seedling establishment and growth. These techniques aim to restore the soil and facilitate the seedling development. The soil was improved with composted sewage sludge and the sowing of herbaceous and shrubby species. These actions, together with the natural colonisation of the surrounding plant species, are expected to enhance ecological restoration of the site.

An integrated monitoring process will confirm or reject this hypothesis. The hydrological and erosivesedimentary behaviour monitoring of the GR rehabilitated area has just started and will be sustained until November 2021. Soil suspended concentration will be measured with point-integrating samplers. Soil erosion will be quantified through volumetric measurements at rills and gullies (Food and Agriculture Organization of the United Nations 1993). Soil humidity at different landform conditions, ridges and swales, will be measured with time domain reflectometry.

Monitoring results will be collated through time to confirm if geomorphic stability behaves at TECMINE as it has at El Machorro (Zapico et al. 2018; Figure 1), Somolinos (Figure 2) or Aurora (Figure 3). To date, it can 
be said that 'natural' and visually appealing landforms have been restored. Figure 10 shows slope aspects mapping of the eastern and western sites, respectively. As it can be seen, GR has restabilised complex and diverse landforms, which should favour a high biodiversity, due to different conditions of solar lighting and soil humidity.

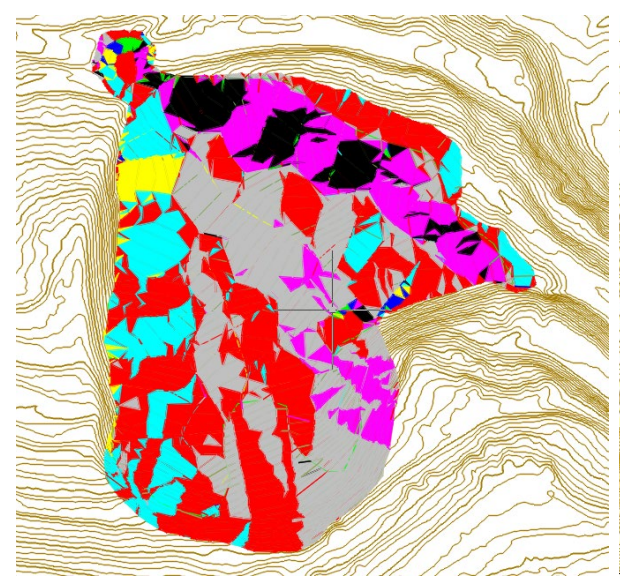

(a)

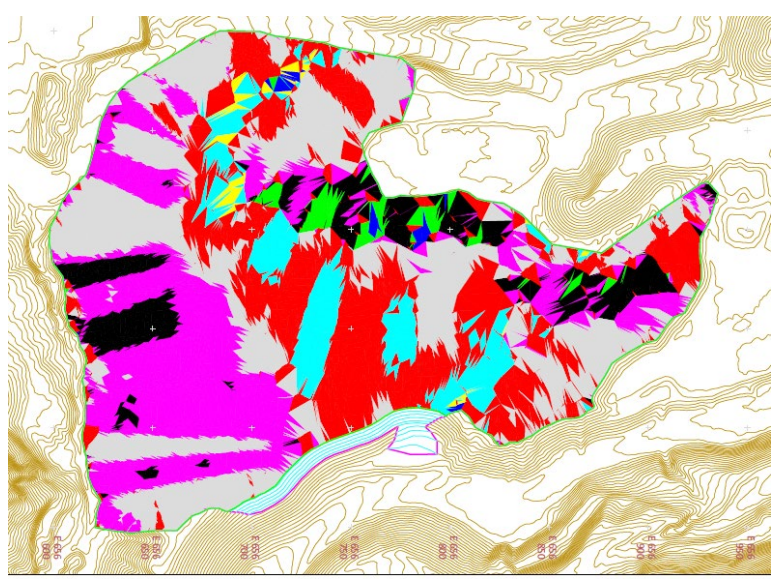

(b)

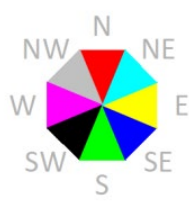

Figure 10 Slope aspect maps for the (a) eastern and (b) western sites of TECMINE. North in upwards position. No scale. See Figures 7 and 8 for correlation

\section{Discussion}

The application of GeoFluv-Natural Regrade GR to mined land in Spain since 2009 has had a critical influence for the recognition of GR by the EC within a catalogue of BATs for the management of waste from extractive industries, in accordance with the European Directive 2006/21/EC (JRC 2018). GR has been recognised as a BAT by the EU because monitoring of specific examples has proven that GR increases physical stability, provides a natural hydrological function, minimises erosion from stormwater and snowmelt runoff, provides variability within a natural landform that promotes ecological diversity for vegetation and wildlife communities, minimises construction, reduces short and long-term maintenance and repair costs, and reduces the visual impact of mine landforms.

GR is receiving high acceptance by regulators. Although not mandatory or compulsory, it is recommended that the mining industry follow the techniques of GR, following the clear support by European administrators and provided by the JRC (2018) guidelines. In Spain, at the Castile-La Mancha and Valencia regions, the mining and environmental regulators are promoting and extending their support for GR. In the Castile-La Mancha Region, where most of the successful cases used for the BAT recognition are located, GR is promoted within a document entitled Code of Management of Practices and Environmental Actions in the Mining Activities of Castile-La Mancha (in accordance with the so-called Plan Estratégico de Recursos Minerales no Energéticos de Castilla-La Mancha, Horizonte 2020, Permine) (DOCLM 2014). A specific paper, authored by the head of its Mining Administration and the Director of the Geomorphic Restoration group of the Complutense University of Madrid (Martín Duque \& De La Villa 2018), compiles the numerous GR cases at Castile-La Mancha.

Obtaining EU funding through the LIFE programme for two GR-based ecological restoration projects at mined sites is also evidence of support for the application of GR. In the Valencia Region, the environmental administration is leading the LIFE TECMINE project and is using it for fostering GR within its territory (www.agroambient.gva.es/es/web/life-tecmine).

For the TECMINE project, we focused here in the landform component of the rehabilitation. This is justifiable as GR is still new practice. But it must be stressed that soil replacement and revegetation are also an essential part of any mine rehabilitation project. 


\section{Conclusion}

The recognition of geomorphic restoration as a BAT for the management of waste from extractive industries at the EU, post analysis of several projects in Spain, demonstrates that GR is a real alternative to the conventional mine techniques applied to rehabilitate mine landforms.

Since monitoring has just started at the TECMINE project, current conclusions are limited to the design and building process:

- Finding 'natural' and 'stable' landforms and landscapes for the TECMINE project, to be used as reference to be replicated in GR, was difficult but possible; the reason is a profound (historical) human transformation of the land (transposable to the rest of Spain and the EU).

- The steep terrain, characteristic of the Iberian Range, challenged the GR GeoFluv-Natural Regrade designs in following the rigorous principles of the method, but the TECMINE project demonstrated that these principles can be carried out and landforms built at that physiographic setting to design.

- The mining company reported similar costs for this alternative GR rehabilitation (as-built) as that for conventional rehabilitation designs (projected).

- A holistic geomorphic approach to mine rehabilitation, not dealing only with topography, but in identifying and using available limestone colluvium as an adequate substrata for initiating soil development, provided a cost-effective and ecologically sound solution not previously used for mine rehabilitation of clay and sand mines at the mountains of Valencia, and was a clear and advanced contribution by the TECMINE project.

In summary, GR implementation at the TECMINE project has demonstrated a true alternative technique to unsuccessful conventional mine rehabilitations in the mines within the Iberian Range of Spain. For those reasons, the Administration of the Valencia Region of Spain is fostering and encouraging the use of GR.

\section{Acknowledgement}

This paper has been funded with the financial contribution of the LIFE program of the EU under the LIFE 16 ENV/ES/000159 TECMINE project (www.agroambient.gva.es/en/web/life-tecmine/inicio). The partners of this project are:

- The Generalitat Valenciana (GVA), a public institution that performs the functions of the Spanish State on environmental matters in the Valencian Community (www.agroambient.gva.es/es).

- The mining company SIBELCO MINERALES, SA, leading producer of silica sands in Spain, belonging to a worldwide mining group headquartered in Antwerp (Belgium) (https://www.sibelco.com/).

- CEAM, a research, development and technological innovation to improve the environment in the Mediterranean region (www.ceam.es/GVAceam/ceam_val/home.htm).

- Vaersa, a public company of the GVA providing all kinds of services related to environmental management, including the development of efficient and respectful environmental management services and new technologies (www.vaersa.com/).

- The Universidad Complutense de Madrid, by means of his transfer and research group on geomorphic restoration (www.restauraciongeomorfologica.es).

The main participants in this project, in addition to the authors of this paper, are acknowledged: Juan Uriol (coordinator) and Eduardo Pérez-Lahorga (GVA); Juan Carlos Santiago, Susana Tejada and Alfredo Soriano (SIBELCO); Beatriz Olmo, Cristina Beseler, Ibán Hurtado, Cristina Gil and Daniel Arizpe (Vaersa); Alberto Villagrosa, Lluna Morcillo and José Antonio Alloza (CEAM). 


\section{References}

Bugosh, N, Martín Duque, JF \& Eckels, R 2016, 'The GeoFluv method for mining reclamation: why and how it is applicable to closure plans in Chile', in J Wiertz \& D Priscu (eds), Proceedings of the First International Congress on Planning for Closure of Mining Operations, Gecamin, Santiago of Chile.

Bugosh, N \& Epp, E 2019, 'Evaluating sediment production from native and fluvial geomorphic reclamation watersheds at La Plata Mine', Catena, vol. 174, pp. 383-398.

DePriest, NC, Hopkinson, LC, Quaranta, JD, Michael, PR \& Ziemkiewicz, PF 2015, 'Geomorphic landform design alternatives for an existing valley fill in central Appalachia, USA: quantifying the key issues', Ecological Engineering, vol. 81, pp. 19-29.

DOCLM 2014, 'Resolución de 12/11/2014, de la Consejería de Fomento, por la que se aprueba el plan estratégico de recursos minerales no energéticos de Castilla-La Mancha. Horizonte 2020 (Permine)', Diario Oficial de Castilla - La Mancha, No. 229, pp. 36149-36336.

Food and Agriculture Organization of the United Nations 1993, Field Measurement of Soil Erosion and Runoff, Rome.

Gagen, PJ \& Gunn, J 1988, 'A geomorphological approach to limestone quarry restoration', in JM Hooke (ed.), Geomorphology in Environmental Planning, John Wiley \& Sons, New York, pp. 121-142.

Hancock, GR, Loch, RJ \& Willgoose, GR 2003, 'The design of postmining landscapes using geomorphic principles', Earth Surface Processes and Landforms, vol. 28, pp. 1097-1110.

Hancock, G, Martín Duque, JF \& Willgoose, G 2019, 'Geomorphic design and modelling at catchment scale for best mine rehabilitation - the Drayton mine example (New South Wales, Australia)', Environmental Software and Modelling, vol. 114, pp. 140-151.

Howard, E, Loch, R \& Vacher, CA 2011, 'Evolution of landform design concepts', Transactions of the Institution of Mining and Metallurgy, Section A: Mining Technology, vol., 120, no. 2, pp 112-117.

Joint Research Centre 2018, Best Available Techniques Reference Document for the Management of Waste from the Extractive Industries in Accordance with 839 Directive 2006/21/EC, Joint Research Centre, European Commission 840.

Kelder, I, Willis, T \& Waygood CG, 2016, 'Integrating the use of natural analogues and erosion modelling in landform design for closure', in AB Fourie \& M Tibbett (eds), Proceedings of the 11th International Conference on Mine Closure, Australian Centre for Geomechanics, Perth, pp. 99-106.

Martín Duque, JF, Sanz, MA, Bodoque, JM, Lucía, A \& Martín-Moreno, C 2010, 'Restoring earth surface processes through landform design. A 13-year monitoring of a geomorphic reclamation model for quarries on slopes', Earth Surface Processes and Landforms, vol. 35, pp. 531-548.

Martín Duque, JF \& De La Villa, J 2018, 'Restauración geomorfológica de espacios afectados por la minería de Castilla - La Mancha. Posibilidades de aplicación a las explotaciones de áridos', Proceedings of 5 Congreso Nacional de Áridos, Federación de Áridos, Santiago de Compostela, pp. 82-90.

Martín-Moreno, C, Tejedor, M, Martín Duque, JF, Nicolau, JM, Bladé, E, Nyssen, S, Lalaguna, L, De Lis, A, Cermeño-Martín, I \& Gómez, JM 2018a, 'Natural drainage basins as fundamental units for mine closure planning: Aurora and Pastor I quarries', in D Priscu, (ed.), Proceedings of the Second International Congress on Planning for Closure of Mining Operations, Gecamin, Santiago, pp. 1-8.

Martín-Moreno, C, Martín Duque JF, Nicolau JM, Muñoz A \& Zapico I 2018b, 'Waste dump erosional landform stability - a critical issue for mountain mining', Earth Surface Processes and Landforms, vol. 43, pp. 1431-1450.

Nicolau, JM 2003, 'Trends in relief design and construction in opencast mining reclamation', Land Degradation and Development, vol. 14, pp. 215-226.

NMMMD 2010, A Method for the Evaluation of Compliance with the Approximate Original Contour Requirements of CSMC RULE 19.8, New Mexico Mining and Minerals Division, Santa Fe.

RIVERMorph 2019, Rivermorph, computer software, viewed 29 March 2019, http://www.rivermorph.com/

Rosgen, DL 1994, 'A classification of natural rivers', Catena, vol. 22, pp. 169-199.

Rosgen, DL 1996, Applied River Morphology, Wildland Hydrology, Pagosa Springs.

Sawatsky, L \& Beckstead, G 1996, 'Geomorphic approach for design of sustainable drainage systems for mineland reclamation'. International Journal of Surface Mining, Reclamation and Environment, vol. 10, no. 3, pp. 127-129.

Toy, TJ \& Chuse, WR 2005, 'Topographic reconstruction: a geomorphic approach', Ecological Engineering, vol. 24, pp. 29-35.

Waygood, C 2014, Adaptative landform design for closure, in IM Weiersbye, AB Fourie \& M Tibbett (eds.), paper presented at the Ninth International Conference on Mine Closure, Johannesburg, 1-3 October 2014.

Zapico, I, Martín Duque, JF, Bugosh, N, Balaguer, L, Campillo, JV, De Francisco, C, García, J, Hernando, N, Nicolau, JM, Nyssen, S, Oria, J, Sanz, MA \& Tejedor, M 2011, 'Geomorphic and habitats reconstruction at the restoration plan of the 'Los Quebraderos de la Serrana Quarry' (Toledo, Spain)', 4th World Conference on Ecological Restoration, Book of Abstracts, Society of Ecological Restoration, Washington, p. 310.

Zapico, I, Martín Duque, JF, Bugosh, N, Laronne, JB, Ortega, A, Molina, A, Martín-Moreno, C, Nicolau, N \& Sánchez, L 2018, 'Geomorphic Reclamation for reestablishment of landform stability at a watershed scale in mined sites: the Alto Tajo Natural Park, Spain', Ecological Engineering, vol. 111, pp. 100-116. 
